\title{
A Wideband High-Gain Dual-Polarized Slot Array Patch Antenna for WiMAX Applications in $5.8 \mathrm{GHz}$
}

\author{
Amir Reza Dastkhosh ${ }^{1}$ and Hamid Reza Dalili Oskouei ${ }^{2}$ \\ ${ }^{1}$ Sahand University of Technology, P.O. Box 51335-1996, Tabriz, Iran \\ ${ }^{2}$ University of Aeronautical Science \& Technology (Shahid Sattari), P.O. Box 13846-63113, Tehran, Iran
}

Correspondence should be addressed to Amir Reza Dastkhosh,amir_reza_dastkhosh@yahoo.com

Received 9 April 2011; Revised 12 May 2011; Accepted 20 July 2011

Academic Editor: Dau-Chyrh Chang

Copyright (C) 2012 A. R. Dastkhosh and H. Dalili Oskouei. This is an open access article distributed under the Creative Commons Attribution License, which permits unrestricted use, distribution, and reproduction in any medium, provided the original work is properly cited.

\begin{abstract}
A low-cost, easy-to-fabricate, wideband and high-gain dual-polarized array antenna employing an innovative microstrip slot patch antenna element is designed and fabricated. The design parameters of the antenna are optimized using commercial softwares (Microwave Office and Zeland IE3D) to get the suitable $S$-parameters and radiation patterns. Finally, the simulation results are compared to the experimental ones and a good agreement is demonstrated. The antenna has an approximately bandwidth of $14 \%$ $(5.15-5.9 \mathrm{GHz})$ which covers Worldwide Interoperability Microwave Access (WiMAX)/5.8. It also has the peak gain of $26 \mathrm{dBi}$ for both polarizations and high isolation between two ports over a wide bandwidth.
\end{abstract}

\section{Introduction}

Recently, microstrip patch antennas are one of the most commonly used antenna types due to many advantages such as light weight, low fabrication costs, planar configuration, and capability to integrate with microwave integrated circuits. Thus, the patch antennas are very suitable for various applications such as wireless communication systems, cellular phones, satellite communication systems, and radar systems [1-6]. Due to their inherent features they are found attractive for applications in broadband networks. WiMAX is a standard-based wireless technology for broadband networks providing high data rate communication by using low-cost equipment. The access points in this network are usually built with large physical spacing. Therefore, the high-gain antenna is necessary to execute the long distance transmission with a lower power. WiMAX has three allocated frequency bands called low band $(2.5 \mathrm{GHz}$ to $2.8 \mathrm{GHz})$, middle band ( $3.2 \mathrm{GHz}$ to $3.8 \mathrm{GHz}$ ), and high band $(5.2 \mathrm{GHz}$ to $5.8 \mathrm{GHz}$ ). In this work, the low-cost microstrip slot array antenna $(8 \times 8)$ is designed, simulated, and fabricated for operation in the frequency band of $5.15 \mathrm{GHz}$ to $5.9 \mathrm{GHz}$. In each antenna element, two rectangular slots are used for coupling the microstrip feed lines to the radiating patch.
This antenna has high isolation between the two ports over a wide bandwidth more than $14 \%$. Furthermore, this highgain $(25.5 \mathrm{dBi})$ array antenna has dual polarization with a minimum half-power beamwidth (HPBW) (vertical: $7^{\circ}$; horizontal: $6^{\circ}$ ). The impedance characteristics, radiation pattern, return loss, and isolation between two ports for the designed array are analyzed, simulated, and optimized using Microwave Office and Zeland IE3D softwares. Also, $S_{11}, S_{21}$, and radiation pattern are measured and compared to the simulated ones.

\section{Configuration of Element Antenna}

Microstrip patch antennas can be excited by different types of feeds. In order to achieve the desired performances of WiMAX antenna, an aperture coupled feed is used because of its good characteristics such as wide operational bandwidth and shielding of the radiation patches. Moreover, an aperture coupled feed yields better gain and radiation pattern for a dual-polarized antenna aimed for wireless applications [7-12]. An exploded view of the dual-polarized microstrip antenna and a simplified equivalent circuit model for an aperture coupled microstrip antenna are shown in Figure 1. 


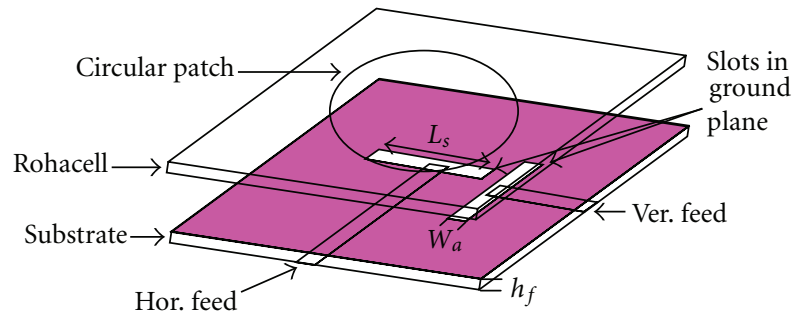

(a)

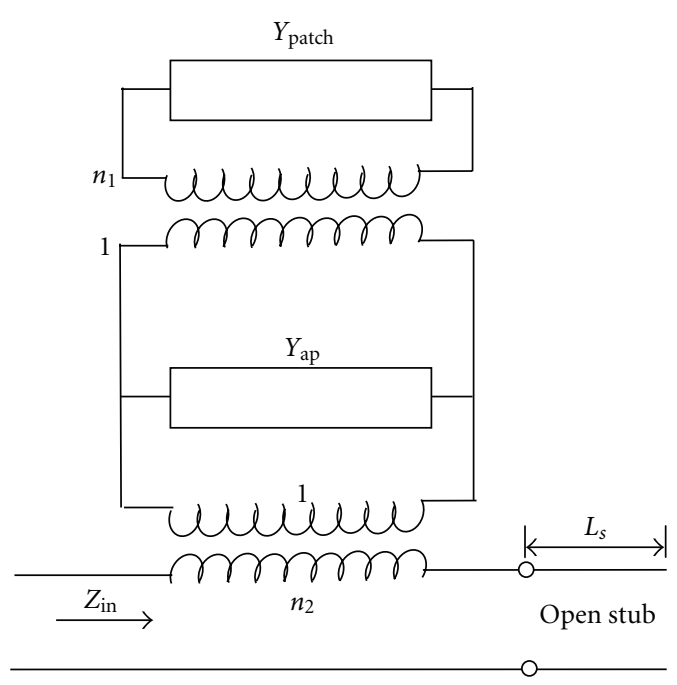

(b)

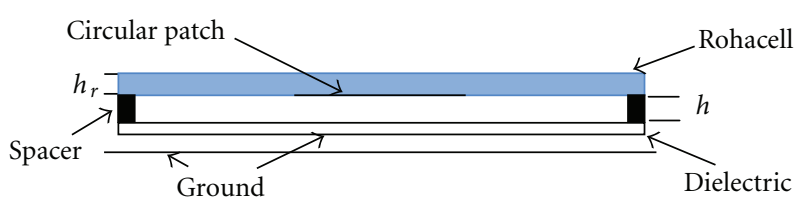

(c)

Figure 1: Configuration of the proposed dual-polarized aperture coupled circular patch antenna; (a) 3D view, (b) simplified equivalent circuit model of an aperture coupled microstrip antenna, and (c) $2 \mathrm{D}$ view Rohacell: $\varepsilon_{r}=1.06, h_{r}=12 \mathrm{~mm}$; substrate: $\varepsilon_{r f}=4.5, h_{f}=$ $0.762 \mathrm{~mm}, h=5.9 \mathrm{~mm}$; vertical and horizontal apertures' dimensions or feed slot $\left(L_{a} \times W_{a}\right): 14 \times 2 \mathrm{~mm}$.

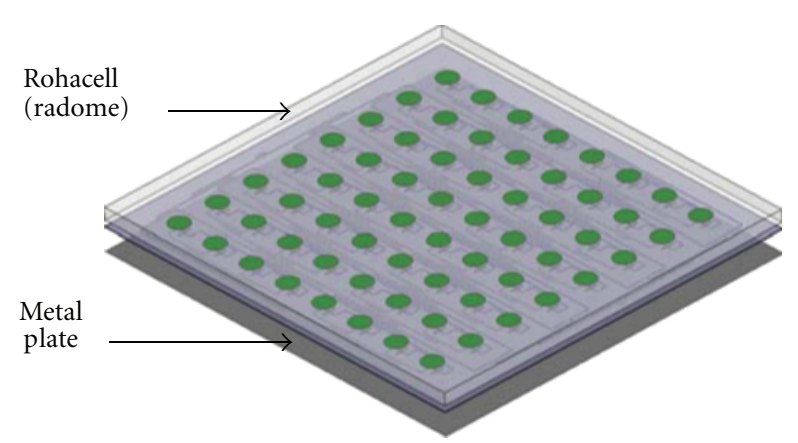

(a)

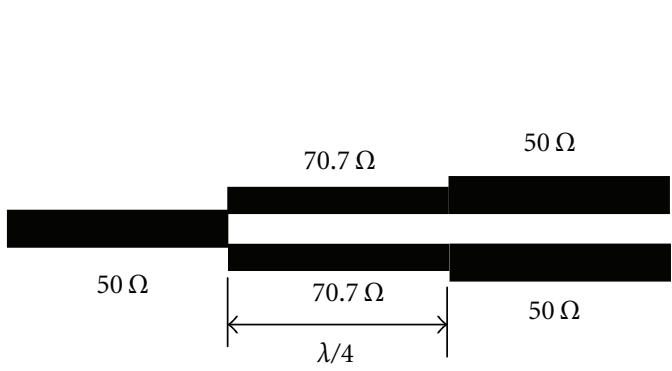

(c)

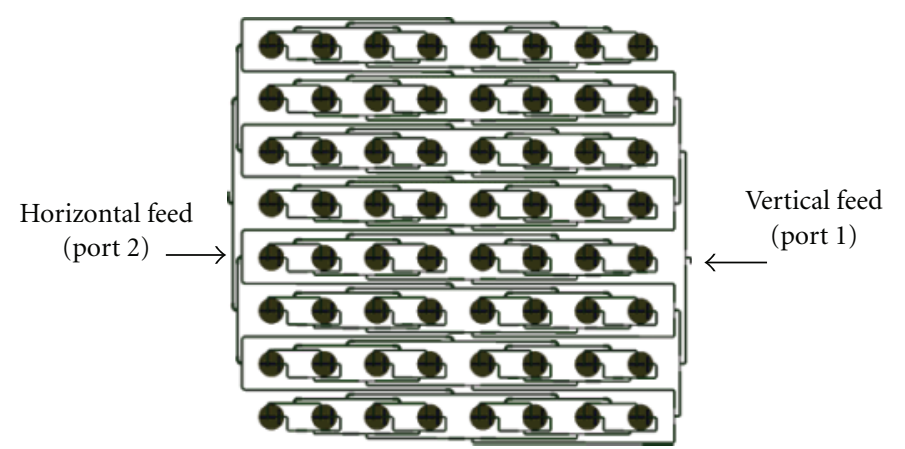

(b)

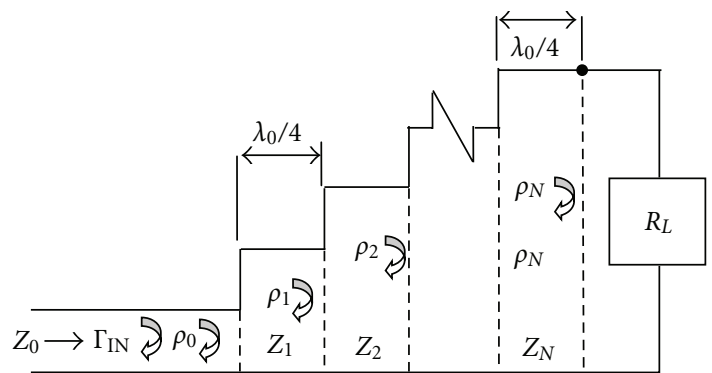

(d)

FIGURE 2: (a) 3D view of $8 \times 8$ array antenna with its ground plane. Rohacell (bottom: circular patches): $\varepsilon_{r}=1.06, h_{r}=12 \mathrm{~mm}$; substrate (top: slots, bottom: feed lines): $\varepsilon_{r f}=4.5, h_{f}=0.762 \mathrm{~mm}$. (b) Feed structure of array antenna. (c) Quarter-wave matching transformer. (d) $N$-section $\lambda / 4$ transformer. 


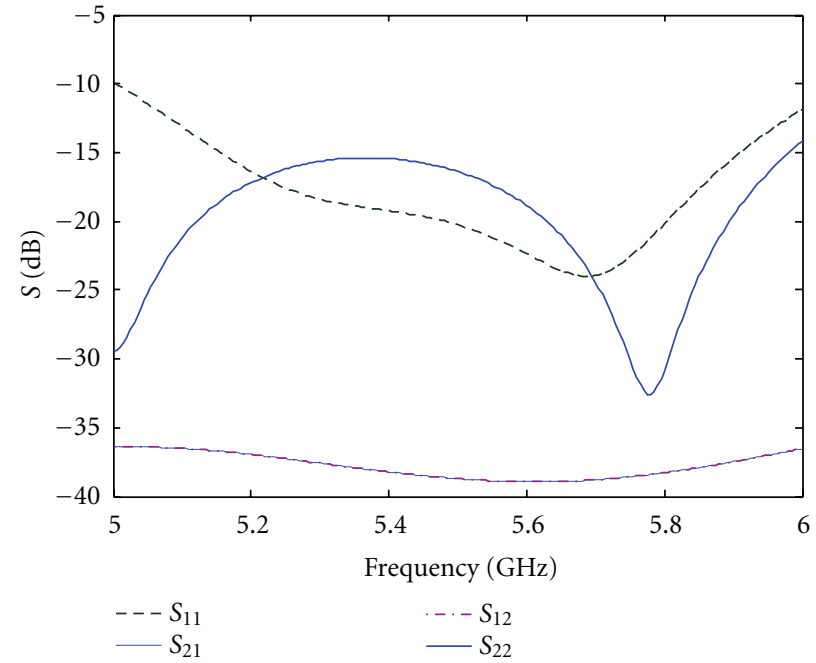

(a)

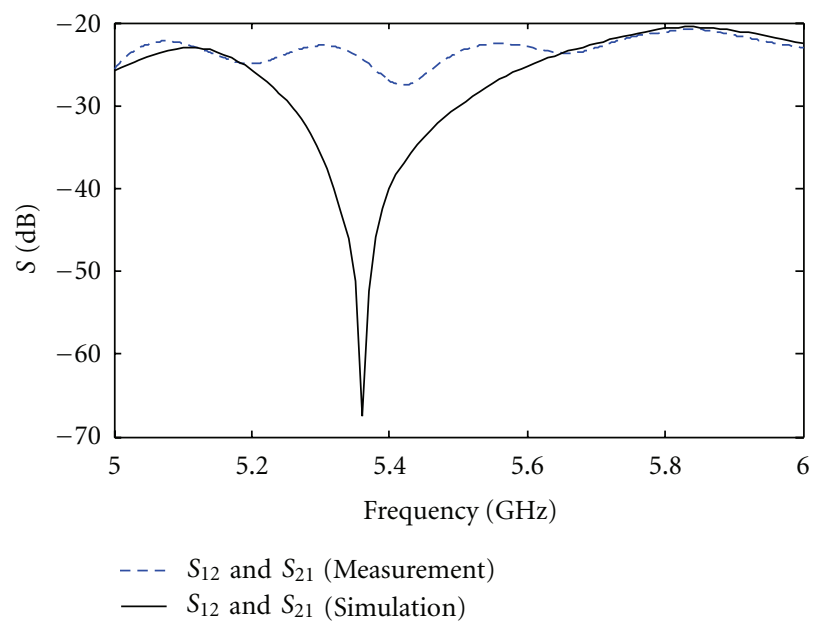

(c)

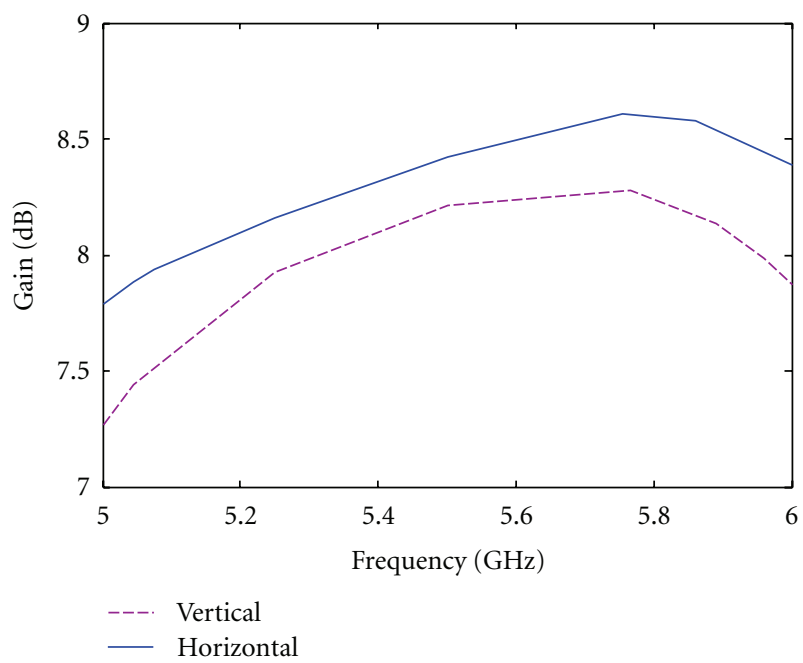

(b)

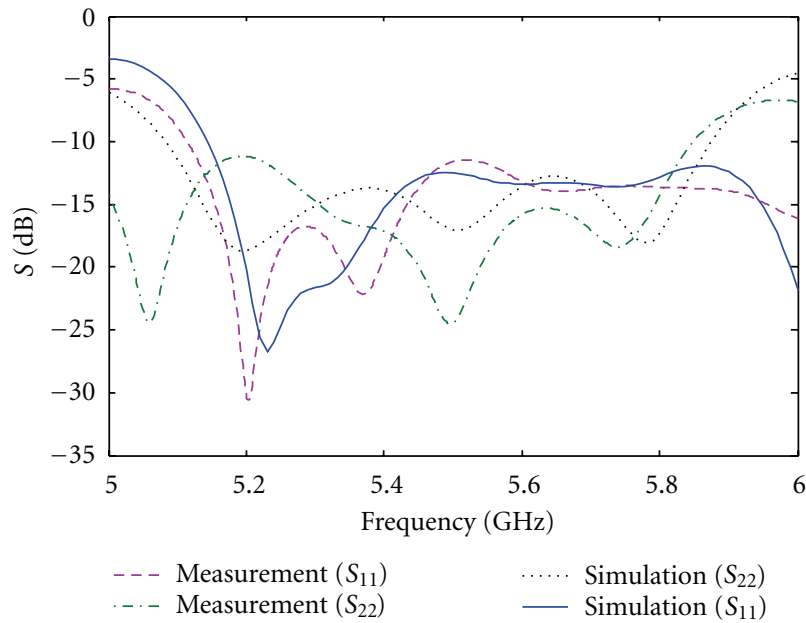

(d)

FIgURE 3: (a) Return loss and isolation versus frequency of one element of dual-polarized antenna element. (b) Gain versus frequency of one element of dual polarized antenna element. (c) Isolation. (d) Return loss versus frequency of $8 \times 8$ array antenna.

TABLE 1: Wideband dual-polarized patch antenna specification.

\begin{tabular}{lc}
\hline Frequency range & $5.15-5.9 \mathrm{GHz}$ \\
Peak gain & $26 \mathrm{dBi}$ \\
Horizontal beamwidth & $6^{\circ}$ \\
Vertical beamwidth & $7^{\circ}$ \\
Front/back ratio & Better than $28 \mathrm{~dB}$ \\
SLL & Vertical: $-11 \mathrm{~dB}($ center frequency) \\
Polarization & Horizontal: $-14 \mathrm{~dB}$ (center frequency) \\
VSWR & (Dual) vertical or horizontal \\
Impedance & $1.9: 1$ (max) \\
Mechanical Specification & 50 Ohms \\
\hline
\end{tabular}

The antenna consists of only one substrate (Rogers TMM 4 with dielectric constant $\left.\varepsilon_{r}=4.5\right)$, an air layer for enhancing the bandwidth, and a radome. The input impedance of the antenna at the center of the slot is given by $[13,14]$

$$
Z_{\text {in }}=\frac{n_{2}^{2}}{n_{1}^{2} Y_{\text {patch }}+Y_{\text {ap }}}-j Z_{0 m} \cot \left(\beta_{m} L_{s}\right),
$$

where $Y_{\text {patch }}$ is the patch admittance and $Y_{\text {ap }}$ is the aperture admittance (Figure $1(\mathrm{~b})$ ). $Z_{0 m}, \beta_{m}$, and $L_{s}$ are the microstrip line parameters in this equation. Also the coupling of the patch to the microstrip line is described by a transformer [14]. The dimensions of the element antenna such as slots, feed lines, circular patch, and spaces between them are optimized with the use of IE3D to achieve best radiation characteristics, wide impedance bandwidth, and high isolation between two ports. The optimized element antenna has a circular patch with $11.89 \mathrm{~mm}$ radius positioned at the bottom side of Rohacell. Furthermore, two $50 \mathrm{ohms}$ microstrip feed lines ( $W=1.5 \mathrm{~mm}, L_{V}=15 \mathrm{~mm}$, and $L_{H}=$ $23 \mathrm{~mm}$ ) at the bottom side of the substrate (Rogers TMM 4 


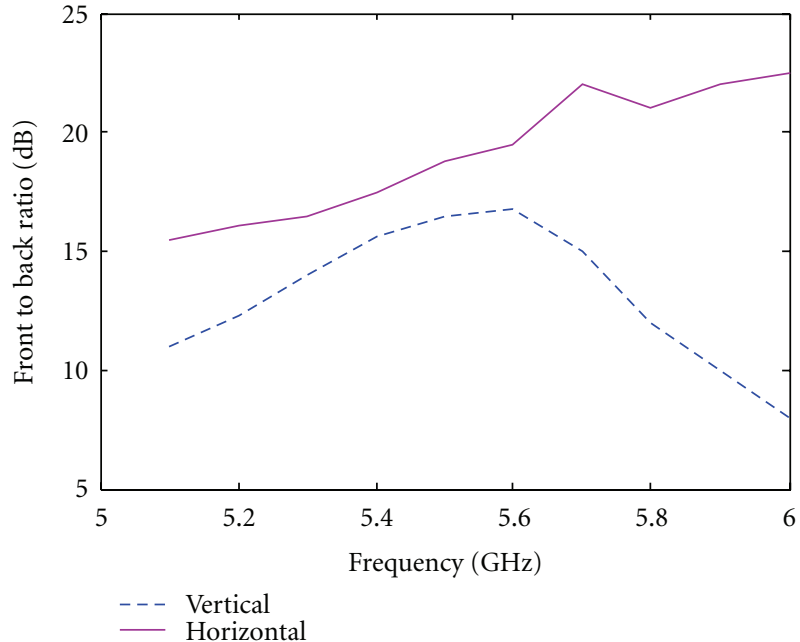

(a)

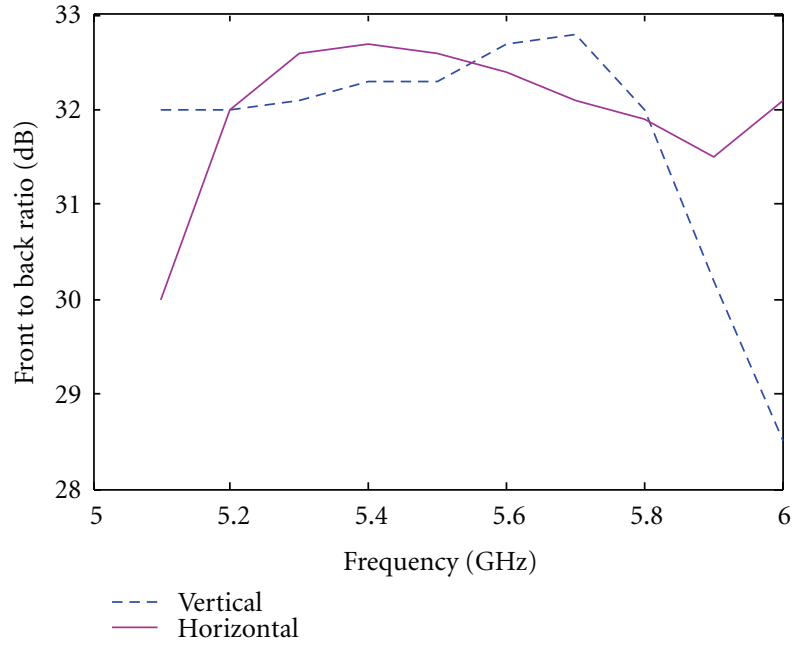

(b)

Figure 4: (a) Simulated front-to-back ratio versus frequency of $8 \times 8$ array antenna without plate at the back of antenna. (b) Measured front-to-back ratio versus frequency of $8 \times 8$ array antenna with metal plate at the back of antenna.

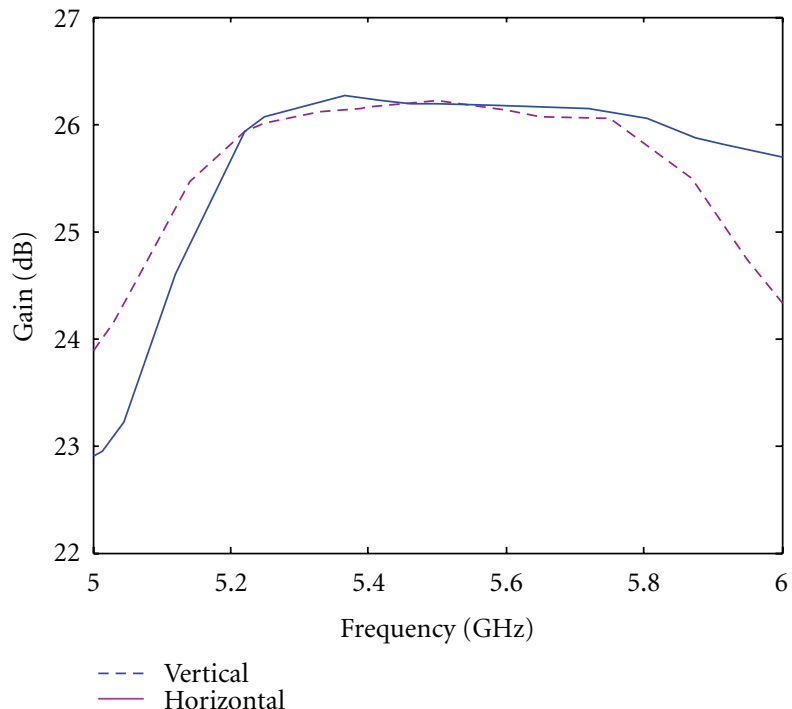

(a)

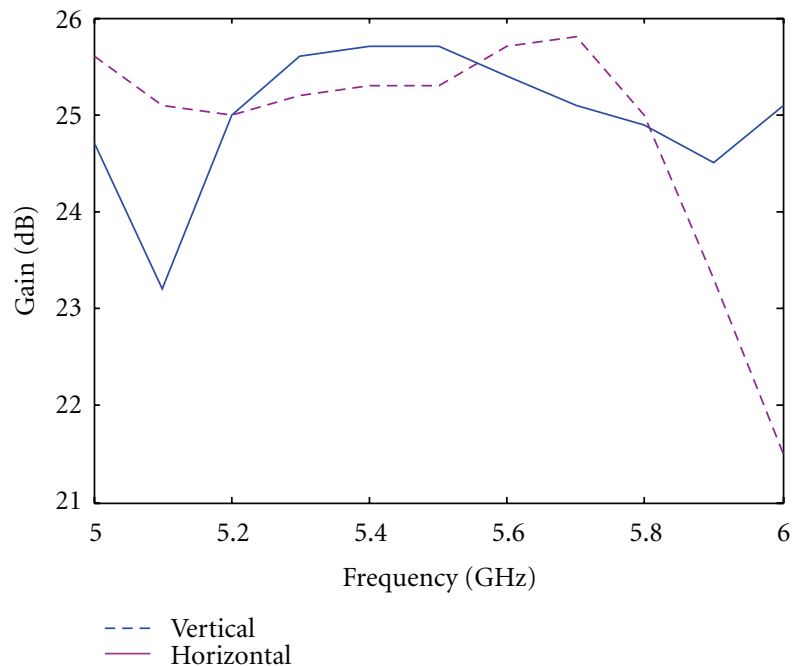

(b)

FiguRE 5: Gain versus frequency of $8 \times 8$ array antenna: (a) simulated and (b) measured.

with $\left.h_{f}=0.762 \mathrm{~mm}, \varepsilon_{r f}=4.5\right)$ are electromagnetically coupled to circular patch through two rectangular slot apertures in the common ground plane. As shown in Figure 2, in order to reduce the antenna back lobes, a metallic plate is located at the back of antenna, for example, $22 \mathrm{~mm}$ from the bottom of the antenna structure. Additionally, Figure 3(a) shows the simulated return loss for two ports $\left(S_{11}\right.$ and $\left.S_{22}\right)$ versus frequency for one element antenna and Figure 3(b) shows simulated gain against frequency for one element. As depicted in Figure 3, in the desired bandwidth (5.1-5.9) return loss for both polarizations is more than $15 \mathrm{~dB}$ and the isolation between two ports $\left(S_{12}\right)$ is better than $35 \mathrm{~dB}$.

\section{Array Antenna}

To obtain the desired radiation pattern characteristics, an $8 \times 8$ planar microstrip slot array antenna is designed (Figure 2(a)). The bottom side of substrate consists of the feeding network which is designed to give equal amplitude and phase to each element (Figure 2(b)). Additionally, by using T-junction design and a quarter-wave matching transformer (Figure 2(c)), the feeds are matched to $50 \mathrm{ohms}$ feed line $[15,16]$. To provide a match, the transformer characteristic impedance $Z_{1}$ should be $Z_{1}=\sqrt{R_{\text {in }} Z_{0}}$, where $Z_{0}$ is the characteristic impedance of the input transmission line and $R_{\text {in }}$ is the input impedance of the antenna. The 


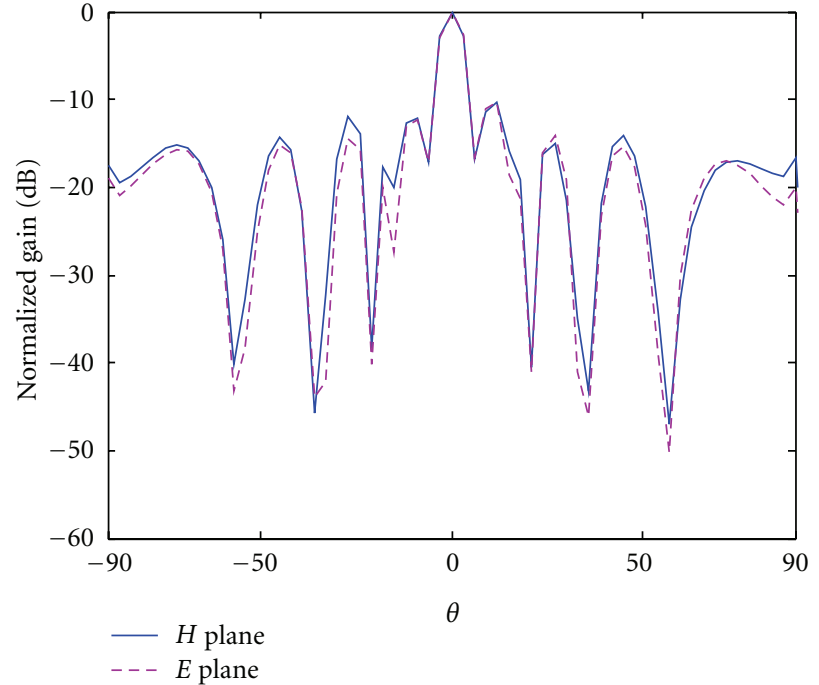

(a)

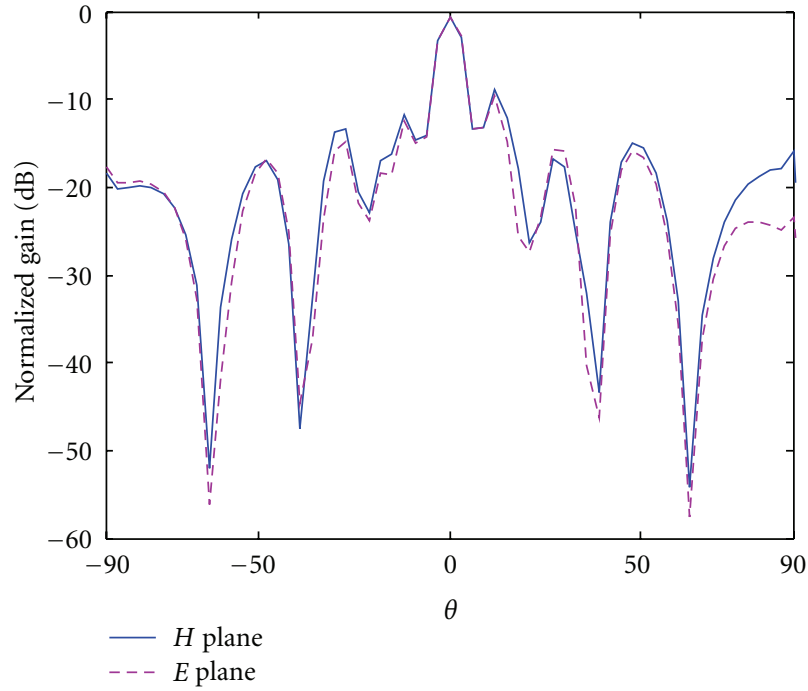

(b)

Figure 6: Simulated antenna far-field radiation pattern at $5.5 \mathrm{GHz}$ : (a) vertical and (b) horizontal.

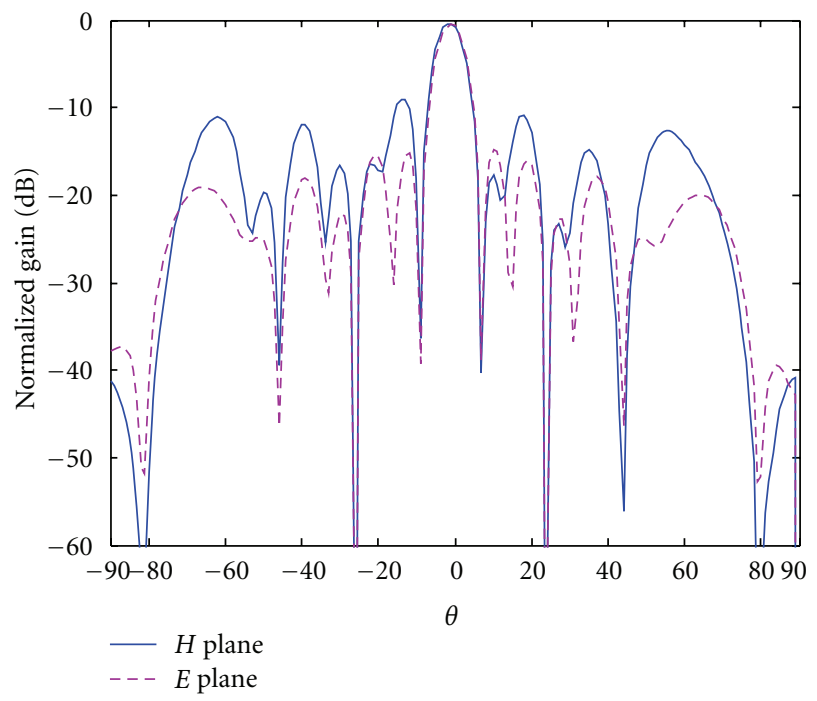

(a)

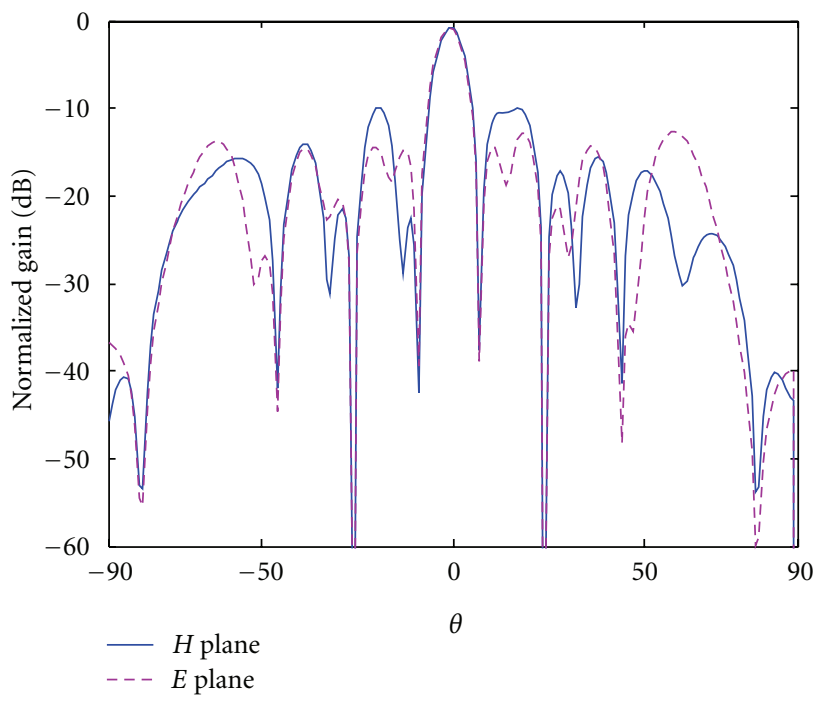

(b)

Figure 7: Measured antenna far-field radiation pattern at $5.5 \mathrm{GHz}$ : (a) vertical and (b) horizontal.

transformer is usually another transmission line with the desired characteristic impedance (Figure 2(d)). The spaces between elements are set at $50 \mathrm{~mm}$ for better radiation characteristics. The simulated and measured return loss $\left(S_{11}\right)$ and isolation $\left(S_{21}\right)$ of $8 \times 8$ dual-polarized microstrip patch slot array antenna are illustrated in Figures 3(c) and 3(d). Furthermore, the metal plate at the back of array antenna reduces the front-to-back ratio about $-20 \mathrm{~dB}$, as can be seen in Figure 4. Likewise, the gain of the array antenna in different frequencies is demonstrated in Figure 5. Moreover, the simulated and measured $E$ and $H$ plane far-field radiation patterns of the array antenna at center frequency are shown in Figures 6 and 7. Finally, all vital parameters such as antenna size, its gain, beamwidth, side lobe level, and frontto-back ratio are summarized in Table 1 .

\section{Conclusions}

This paper has reported the design of a low-cost high-gain dual-polarized patch array antenna for WiMAX applications in the $5.15-5.9 \mathrm{GHz}$ frequency band. The antenna has an approximately bandwidth of $14 \%$ and the peak gain of $26 \mathrm{dBi}$ for both polarizations. The design has been achieved with the use of commercial software packages AWR Microwave Office and Zeland IE3D. The design process aimed at best return losses and fine quality radiation characteristics over 
the assumed frequency band. The designed antenna has an impedance bandwidth of approximately $14 \%$ and the peak gain of approximately $26 \mathrm{dBi}$ for both polarizations. This performance has been confirmed experimentally.

\section{References}

[1] C. A. Balanis, Antenna Theory, Analysis and Design, John Wiley \& Sons, 3rd edition, 2005.

[2] K. L. Wong, Planar Antennas for Wireless Communications, John Wiley \& Sons, 2003.

[3] S. B. Chen, Y. C. Jiao, W. Wang, and F. S. Zhang, "Modified Tshaped planar monopole antennas for multiband operation," IEEE Transactions on Microwave Theory and Techniques, vol. 54, no. 8, pp. 3267-3270, 2006.

[4] W. C. Liu and C. F. Hsu, "Dual-band CPW-fed Y-shaped monopole antenna for PCS/WLAN application," Electronics Letters, vol. 41, no. 7, pp. 390-391, 2005.

[5] W. C. Liu, "Broadband dual-frequency meandered CPW-fed monopole antenna," Electronics Letters, vol. 40, no. 21, pp. 1319-1320, 2004.

[6] J. Y. Li, J. L. Guo, Y. B. Gan, and Q. Z. Liu, "The triband performance of sleeve dipole antenna," Journal of Electromagnetic Waves and Applications, vol. 19, no. 15, pp. 2081-2092, 2005.

[7] K. M. Z. Shams, M. Ali, and H. S. Hwang, "A planar inductively coupled bow-tie slot antenna for WLAN application," Journal of Electromagnetic Waves and Applications, vol. 20, no. 7, pp. 861-871, 2006.

[8] C. Y. Wu, S. H. Yeh, and T. H. Lu, "Novel high gain metamaterial antenna radome for WiMAX operation in the 5.8-GHz band," in IEEE Antennas and Propagation Society International Symposium (AP-S '07), pp. 3488-3491, June 2007.

[9] L. N. Zhangl, S. S. Zhongl, and X. L. Liang, "Dual-band dualpolarized hybrid antenna array," in PIERS Proceedings, Xi'an, China, March 2010.

[10] S. D. Targonski, R. B. Waterhouse, and D. M. Pozar, "Design of wide-band aperture-stacked patch microstrip antennas," IEEE Transactions on Antennas and Propagation, vol. 46, no. 9, pp. 1245-1251, 1998.

[11] D. M. Pozar and S. D. Targonski, "A shared-aperture dualband dual-polarized microstrip array," IEEE Transactions on Antennas and Propagation, vol. 49, no. 2, pp. 150-157, 2001.

[12] H. J. Song and M. E. Bialkowski, "Ku-band $16 \times 16$ planar array with aperture-coupled microstrip-patch elements," IEEE Antennas and Propagation Magazine, vol. 40, no. 5, pp. 25-29, 1998.

[13] G. Vetharatnam, C. B. Kuan, and C. H. Teik, "Combined feed network for a shared-aperture dual-band dual-polarized array," IEEE Antennas and Wireless Propagation Letters, vol. 4, no. 1, pp. 297-299, 2005.

[14] R. Garg and P. Bhartia, Microstrip Antenna Design Handbook, Artech House, 2001.

[15] B. N. Das and K. K. Joshi, "Impedance of a radiating slot in the ground plane of a microstripline," IEEE Transactions on Antennas and Propagation, vol. 30, no. 5, pp. 922-926, 1982.

[16] J. R. James and P. S. Hall, Handbook of Microstrip Antennas, IEE Electromagnetic Waves, Peter Peregrinus, 1989. 

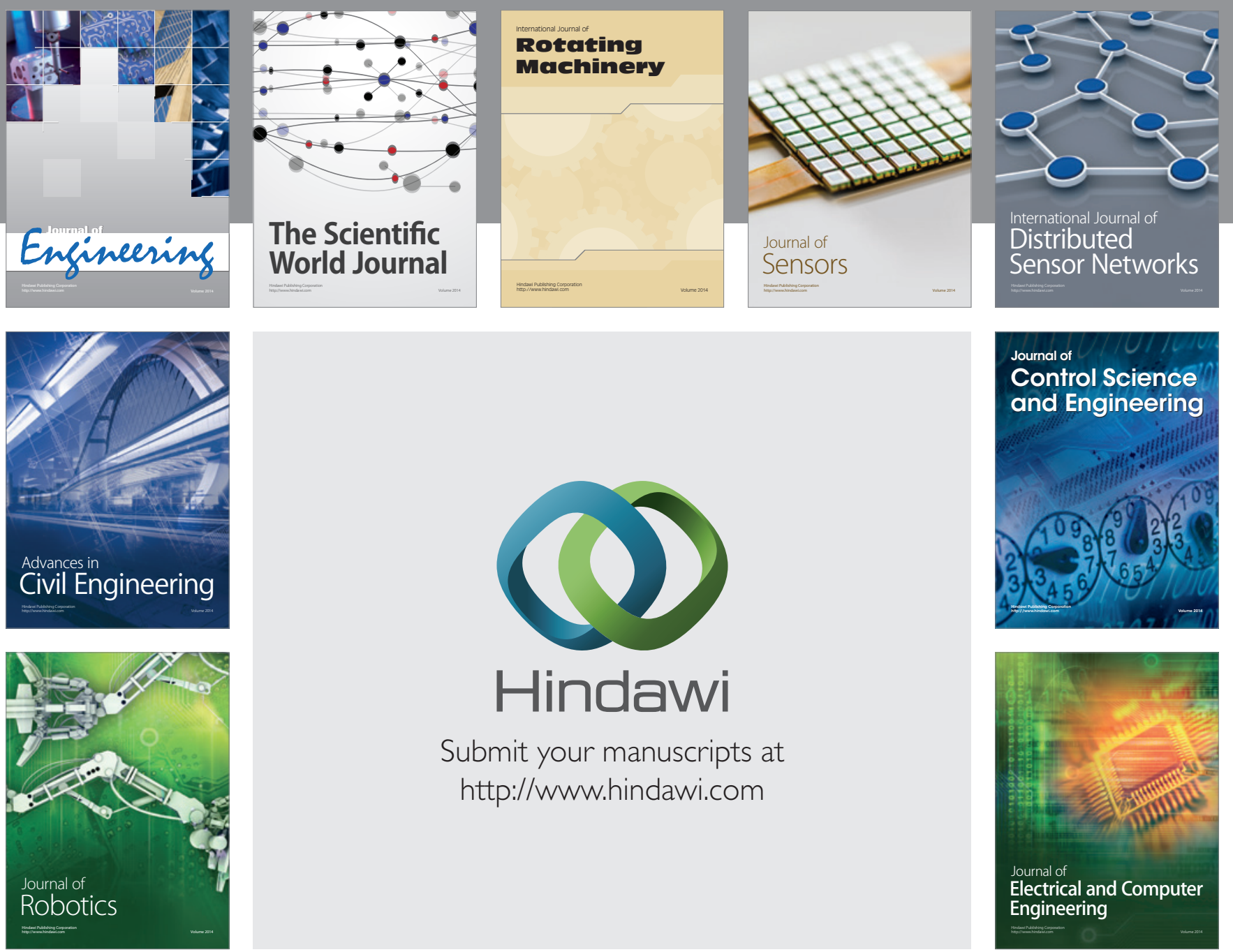

Submit your manuscripts at

http://www.hindawi.com
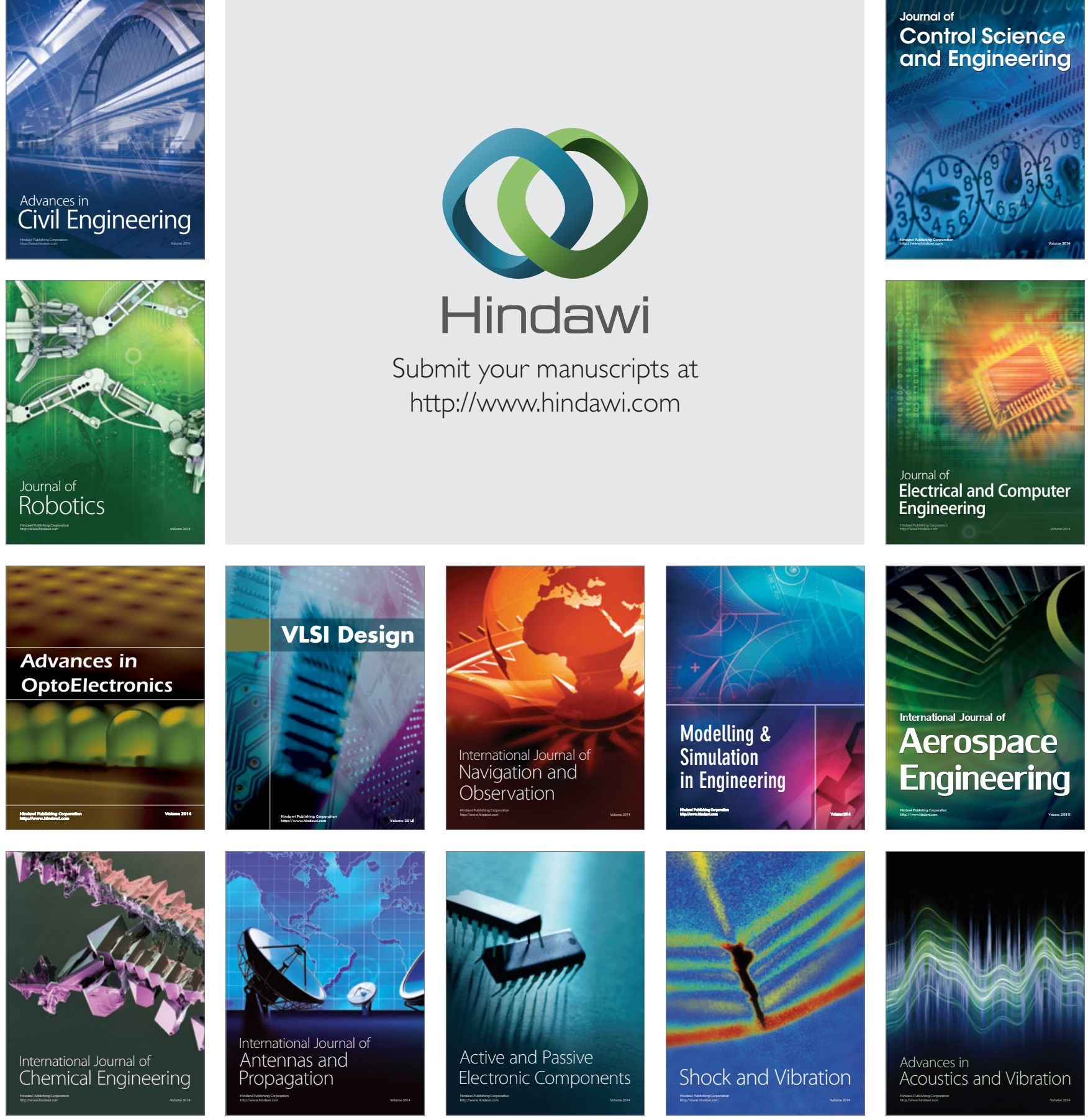